\title{
Punch Flanging Technology for Aluminum Alloy Plate-wheels Rolled Lip Forming
}

\author{
Yong-Cun $\mathrm{PEI}^{1}$, Yong-Sheng $\mathrm{PEI}^{2}$, a , Li-Cong WANG ${ }^{2}$, Shi-Song RUAN ${ }^{2}$ \\ ${ }^{1}$ School of mechanical engineering, Beihua University, city of jilin 132013, China \\ ${ }^{2}$ College of Vehicles and Energy, Yanshan University, Qinhuangdao, Hebei 066004, China \\ a1475425304@qq.com \\ ${ }^{*}$ Corresponding author
}

Keywords: Rolled lip, Aluminium alloy plate-wheels, Punch flanging technology, Finite element models.

\begin{abstract}
Rolled lip is needed to enhance intensity, rigidity and aesthetic feeling of aluminium alloy plate-wheels. The exacting requirements of rolled lip make the forming technology complex. And the forming process is difficult to control. Punch flanging technology adopted to form rolled lip of aluminium alloy plate-wheels was researched and simulated. 3-D elastic-plastic finite element models were constructed and appropriate boundary conditions were given out. The reasons for edge collapse, conner collapse and out of tolerance of run-out in end face are analysed. The results show that rolled lip of aluminium alloy plate-wheels with good forming quality can be formed by one time darwing and $30^{\circ}-60^{\circ}-90^{\circ}$ three times flanging technology.
\end{abstract}

\section{Introduction}

Aluminum alloys are widely utilized in automotive and aircraft industry due to their various advantages such as lightness, good forgeability, high wear resistance, etc.[1 3], In the case of wheels, the increased utilization of aluminum alloys relates predominantly to improved aesthetic appearance and design flexibility over the traditional stamped and welded steel wheels. Greater than $50 \%$ of the new cars in North America are now equipped with aluminum alloy wheels[4]. so, aluminum alloy wheels have a large market now.

The aluminium alloy plate-wheels are a new kind of wheels without inner tube, but with light-weight, energy-saving and environmental protection, which is taking palce of forging and casting aluminum wheels in kart, sandbeach car, mountaineering car, golf car now. Aluminium alloy plate-wheels generally are welded together by two hemi-wheels fabricated by muti-passes plate-spinning technology[5].

Rolled lip is needed to enhance intensity, rigidity and aesthetic feeling of plate-wheels. Spinning is a conventional technology to form rolled lip, but the outline dimension and run-out of rolled lip in end face are difficult to meet the exacting requirements of wheels blueprint.

In this paper, punch flanging technology is applied to form the rolled lip of aluminium alloy plate-wheels. Edge collapse, conner collapse and out of tolerance of run-out in end face generated in simulation and experiment. The reasons for the flaws were studied by finite element simulation and experiment methods. And the effect regularity of flanging times, mould angle and punch stroke on forming quality of rolled lip were discovered.

\section{Experimental}

The 6060-O aluminium alloy was applied for plate-wheels forming. The properties are shown in Table1. 
Tab.1 Parameters of material properties

\begin{tabular}{lccccc}
\hline Materials & $\begin{array}{c}\text { Tensile } \\
\text { strength } \\
(\mathrm{MPa})\end{array}$ & $\begin{array}{c}\text { Yield } \\
\text { strength } \\
(\mathrm{MPa})\end{array}$ & $\begin{array}{c}\text { Elongation } \\
(\%)\end{array}$ & $\begin{array}{c}\text { Elastic } \\
\text { modulus } \\
(\mathrm{GPa})\end{array}$ & Poisson's ratio \\
\hline $6060-\mathrm{O}$ & 130 & 55 & $25-30$ & 71 & 0.31 \\
\hline
\end{tabular}

The experiment equipment is YA100 machine with $1000 \mathrm{kN}$ nominal pressures. Self-designed punch flanging dies were used during punch flanging procedure, which is shown in Fig.1(a).plan of punch flanging technology is shown in Fig.1(b). The mixture of grease and graphite was used as lubricants[6 7]. Samples formed by multi-passes spinning with good standard lip quality and dimension accuracy are shown in Fig.2.

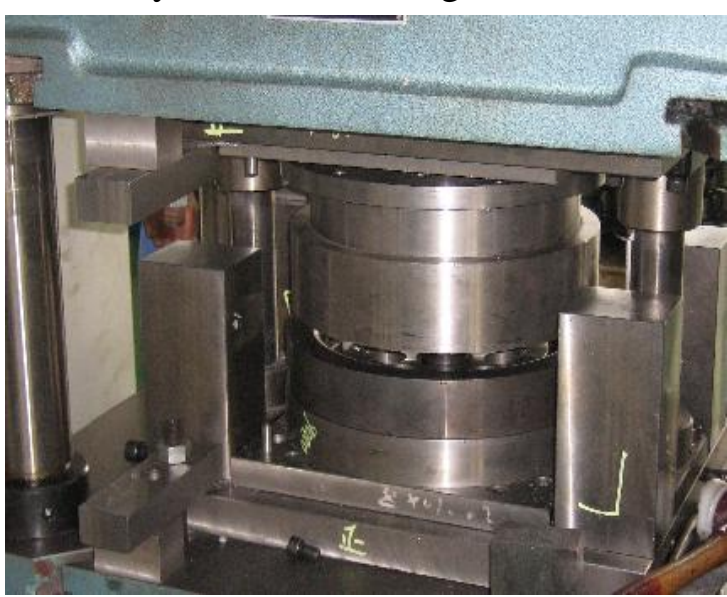

(a)punch flanging die

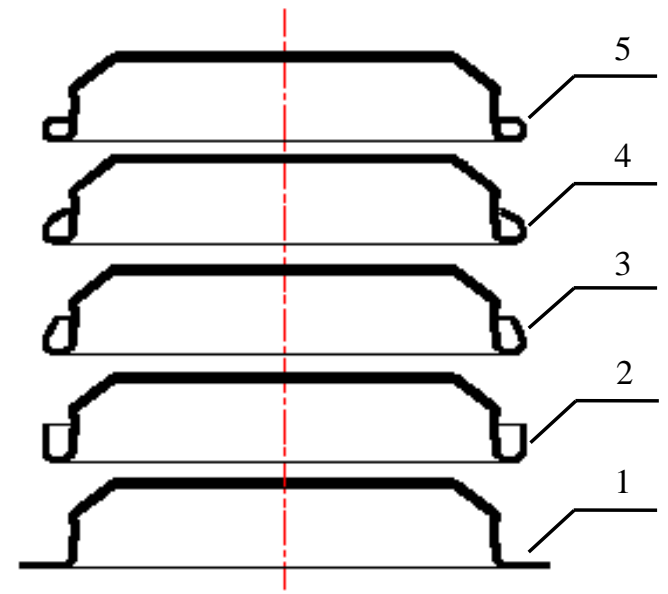

(b) schematic plan of punch flanging technology

1. standard lip billets 2 . one time drawing $3.30^{\circ}$ flanging $4.60^{\circ}$ flanging $5.90^{\circ}$ flanging

Fig.1 Punch flanging technology

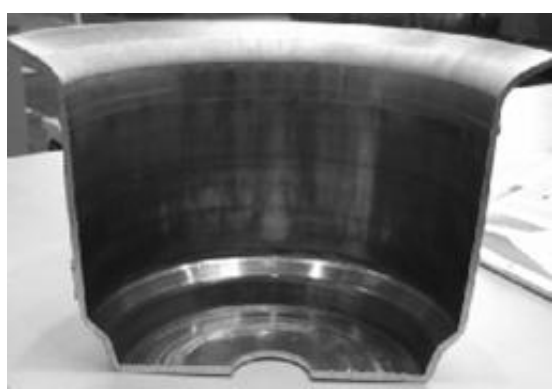

(a) section schematic plan of deep hemi-wheel

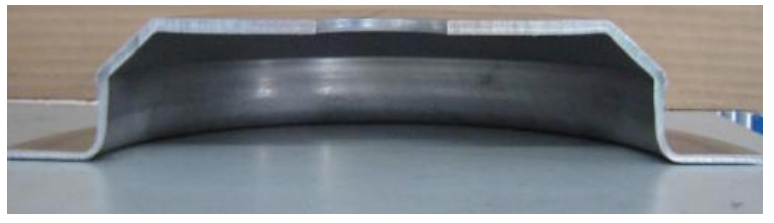

(b) section schematic plan of shallow hemi-wheel

Fig.2 The billets with standard lip

\section{Results and Discussion}

\section{Finite Element Model}

According to punch theory and manufacture experience, mould angle, punch stroke and flanging times have determinant effect on punch flanging technology. Different processing parameters

\footnotetext{
${ }^{1}$ The schematic Project supported by the natural science foundation of Hebei Province (E2015203002).
} 
adopted in the simulation and experiment are shown in Table2.

Based on the forming characteristics of the punch flanging, a 3D elastic-plastic finite element model is established by means of MSC.Marc. The deformable-rigid contact pairs are set between the samples and female die, samples and male die. Take the female die and male die as rigid, the samples as deformable. The 3D finite element model is shown in Fig.3, 11346 elements were divided to calculate finite element [8 10]. Due to the same outline dimension of two hemi-wheels rolled lip, only punch flanging process for shallow hemi-wheel is simulated and researched, the results are universal to the other hemi-wheel.

Tab.2 Parameters of numerical simulation and experiment

\begin{tabular}{cc}
\hline Parameters & Numerical value \\
\hline $\begin{array}{c}\text { Temperature } \\
\text { Diameter of standard lip fabricated } \\
\text { by cutting }\end{array}$ & $20^{\circ} \mathrm{C}$ \\
Thickness of standard lip fabricated \\
by spinning & $320 \pm 0.05 \mathrm{~mm}$ \\
Angle of mould & $3.2 \pm 0.1 \mathrm{~mm}$ \\
Punching stroke & $0^{\circ}-45^{\circ}-90^{\circ}, 0^{\circ}-30^{\circ}-60^{\circ}-90^{\circ}$ \\
Drawing times & 5,10 and $15 \mathrm{~mm}$ \\
Flanging times & 1 \\
Drawing speed & 2 and 3 \\
Flanging speed & $10 \mathrm{~mm} / \mathrm{s}$ \\
\end{tabular}

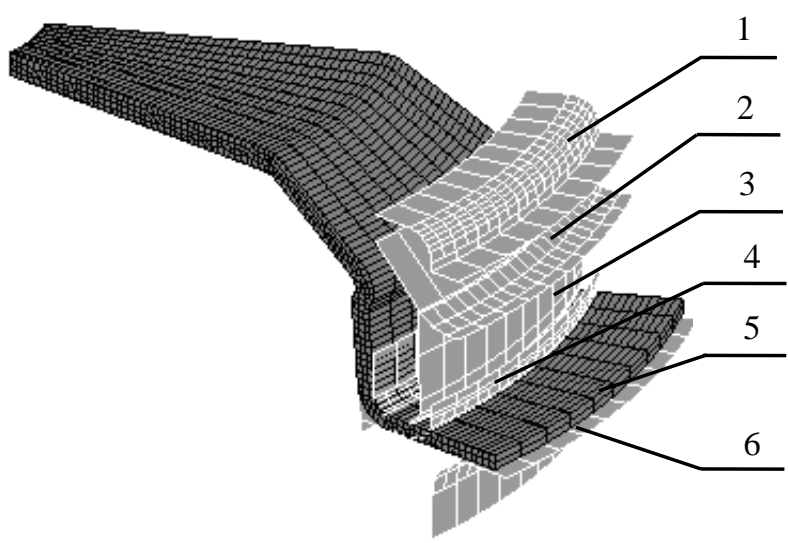

(a) one time drawing and two times flanging

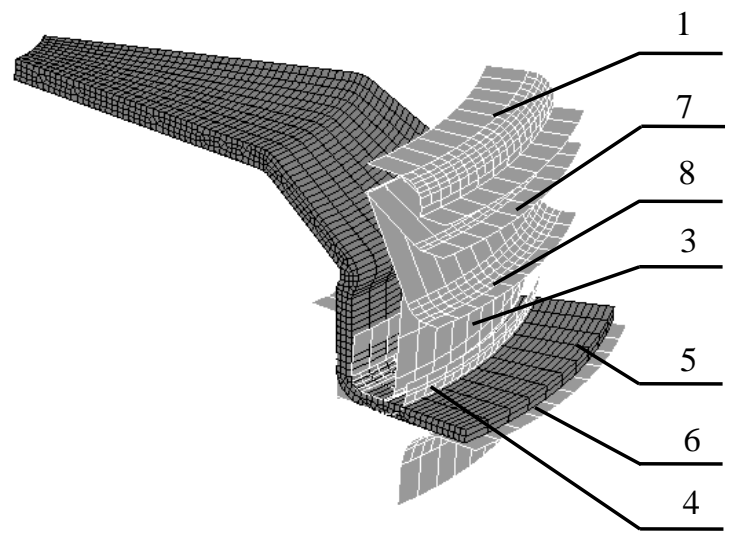

(b) one time drawing and three times flanging

1. $90^{\circ}$ flanging male die $2.45^{\circ}$ flanging male die 3 . drawing male die 4 . flanging female die 5. standard lip billet 6 . drawing female die $7.60^{\circ}$ flanging male die $8.30^{\circ}$ flanging male die

Fig.3 Finite element model

\section{Effect of Flanging Times on Forming Quality of Rolled Lip}

Flanging times have significant effect on the quality of rolled lip and economic performance. The cost of production and forming quality reduce with the decrease of flanging times. According to simulation and experiment, one time drawing and three times flanging technology is appropriate.

The simulation result of one time drawing and two times flanging forming is shown in Fig.4. From Fig.4, edge collapse and conner collapse generate in the area of rolled lip. The same flaws also generate in experiment. 


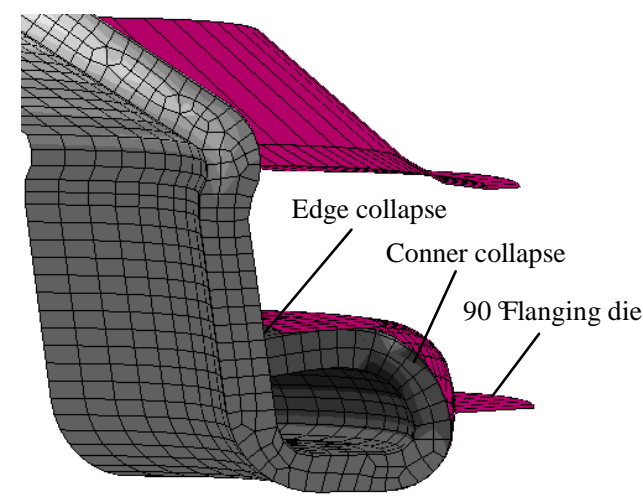

(a)forming flaws

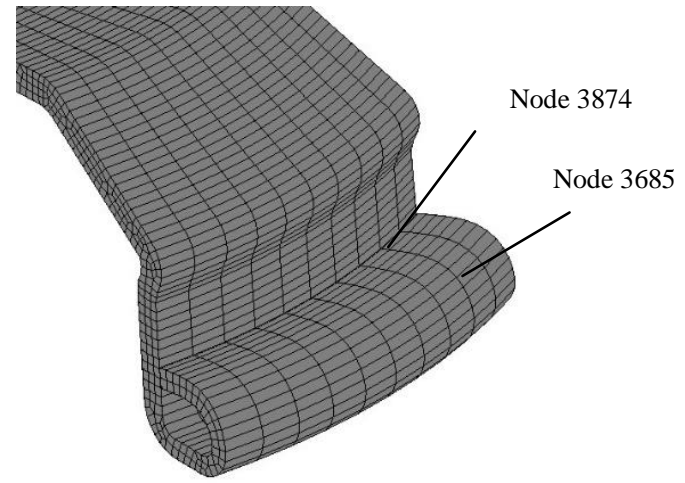

(b)finite element model

Fig.4 One time drawing and two times flanging technology

Node 3874 and node 3685 are adopted in the simulation, which are located in the crest and corner of rolled lip. The change curves of axial displacement with time in different flanging times for node 3874 are shown in Fig.5. From Fig.5, the axial displacement exceeds theoretical value $-9 \mathrm{~mm}$, which is the reason for edge collapse. The change curves of total displacement with time in different flanging times for node 3685 are shown in Fig.6. It shows that the total displacement of two times flanging techonlogy greater than three times flanging techonlogy is the reason for conner collapse.

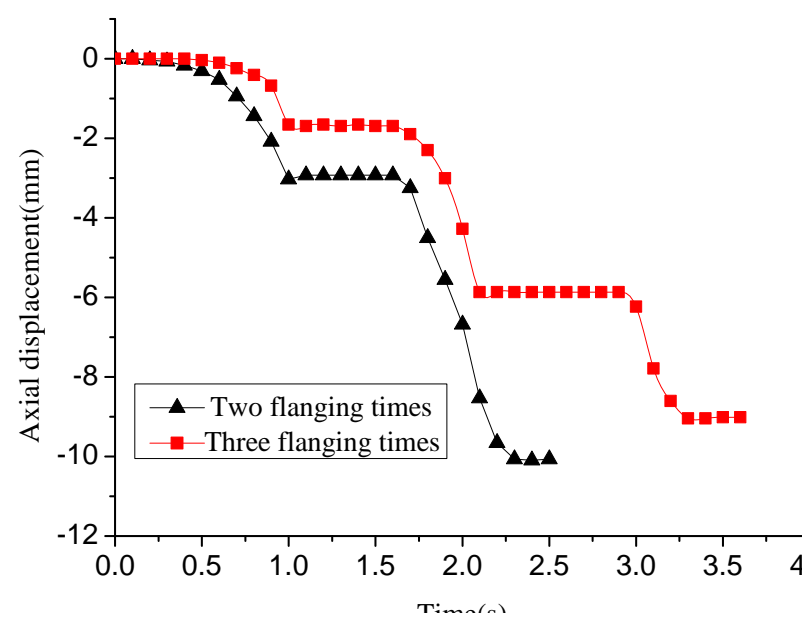

Fig.5 Change curves of axial displacement with time in different flanging times for node 3874

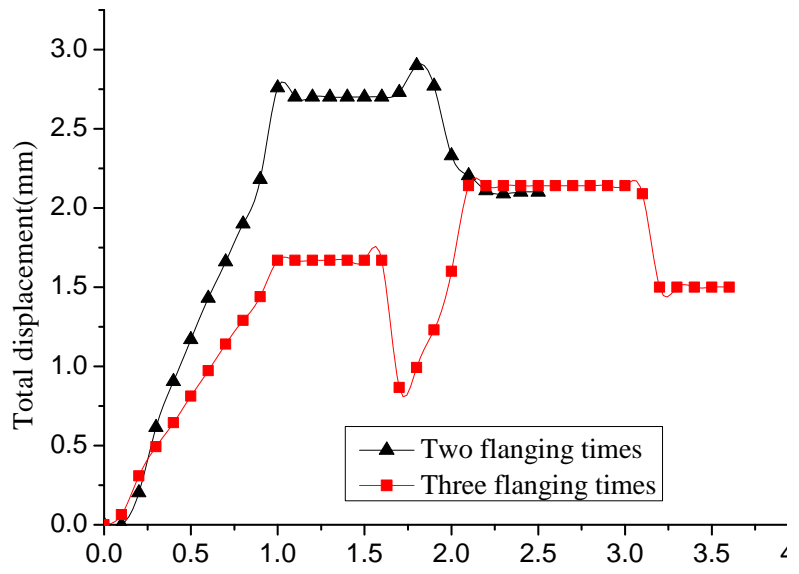

Fig.6 Change curves of total displacement with time in different flanging times for node 3685

\section{Effect of Mould Angle and Punch Stroke on Forming Quality of Rolled Lip}

Edge collapse, conner collapse and out of tolerance of run-out in end face generate when mould angle and punch stroke are irrational. According to simulation and experiment, the one time drawing and $30^{\circ}-60^{\circ}-90^{\circ}$ three times flanging technology is appropriate for aluminium alloy plate-wheels rolled lip forming. Only $30^{\circ}$ punch stroke within the limits $3 \sim 7 \mathrm{~mm}, 60^{\circ}$ punch stroke within the limits $5 \sim 6 \mathrm{~mm}$ and $90^{\circ}$ punch stroke within the limits $9 \pm 0.8 \mathrm{~mm}$, qualified rolled lip can be obtained.

The deformation degree of second flanging has key effect on the quality of rolled lip. Only the deformation degree of second flanging is kept in proper extent, qualified rolled lip can be obtained. Serious edge collapse and out of tolerance of run-out in end face occur when the deformation degree of second flanging exceeds the proper extent, which are shown in Fig.7. The forming process can not proceed when the deformation degree of second flanging is too small, which can be seen in Fig.8. 


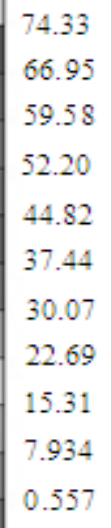

7.934

0.557

(a) deformation degree of second flanging

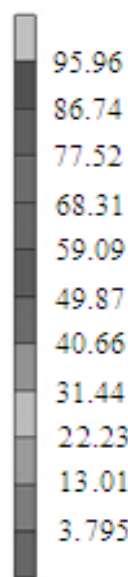

86.74

77.52

68.31

59.09

49.87

40.66

31.44

22.23

13.01

3.795

Fig.7 Edge collapse and out of tolerance of run-out in end face

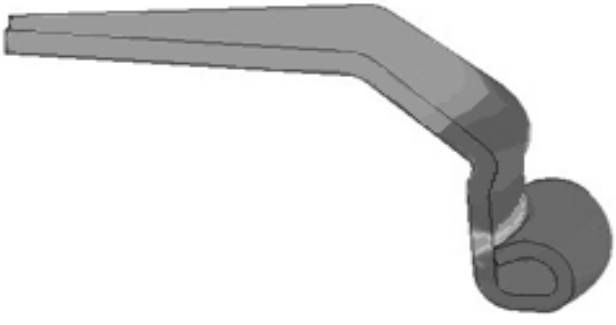

(b) unqualified rolled lip

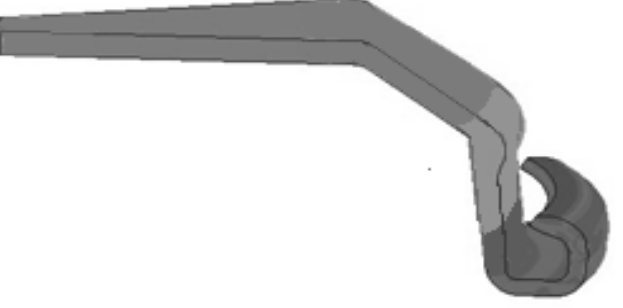

Fig.8 Failed forming process

\section{Distribution of Stress and Strain}

Fig. 3 shows the equivalent total strain of rolled lip after one time drawing and $30^{\circ}-60^{\circ}-90^{\circ}$ times flanging. From Fig.9, high plastic strain presents in the area of rounded corner and end face.

The equivalent Von Mises stress of rolled lip is shown in Fig.10. It shows that the distribution of the equivalent Von Mises stress along the circumferential direction is basically uniform and the plastic deformation concentrated in the area of rolled lip. 


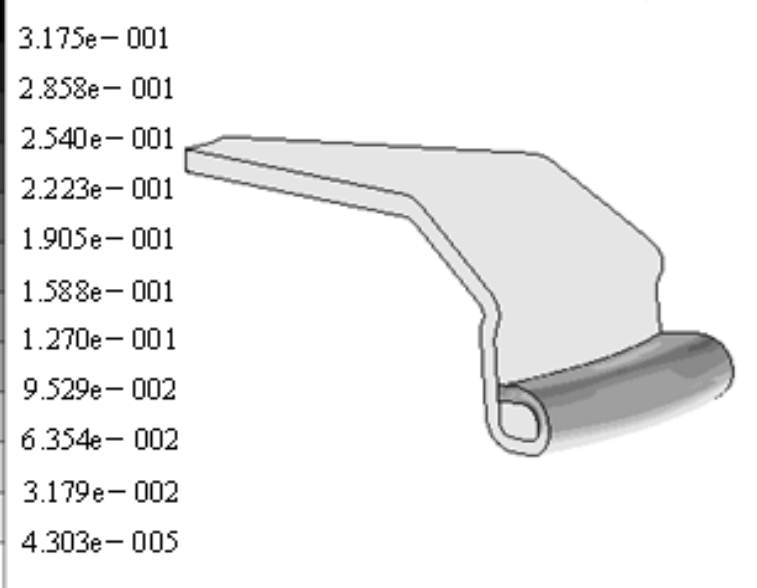

Fig.9 The equivalent total strain

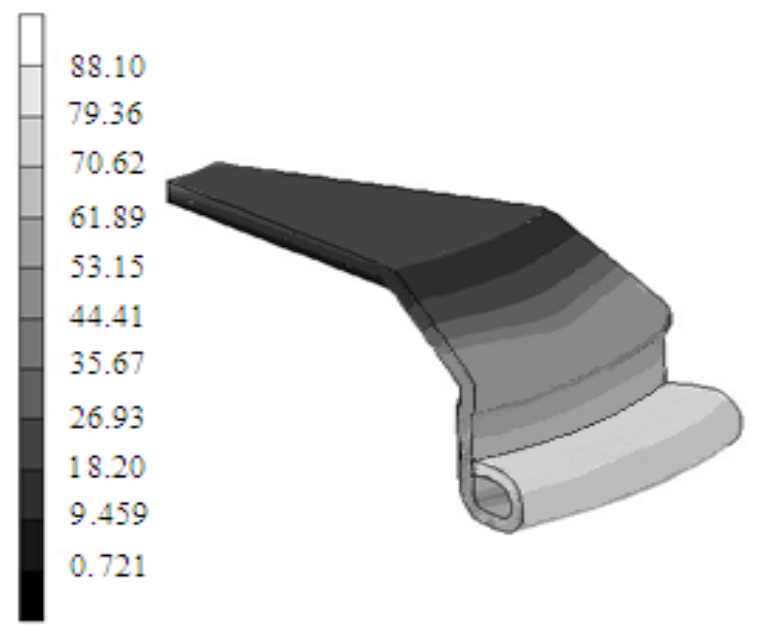

Fig.10 The equicalent Von Mises stress

\section{Conclusion}

1) Rolled lip of aluminium alloy plate-wheels with good forming quality can be formed by one times darwing and $30^{\circ}-60^{\circ}-90^{\circ}$ three times flanging technology.

2) 3-D elastic-plastic finite element models of one time drawing and $30^{\circ}-60^{\circ}-90^{\circ}$ three times flanging are created by MSC.Marc. The effect of flanging times, mould angle and punch stroke on forming quality of rolled lip are researched.

3) The reasons for edge collapse, conner collapse and out of tolerance of run-out in end face are analysed.

4) The deformation degree of second flanging has key effect on the quality of rolled lip. Only the deformation degree of second flanging is kept in proper extent, qualified rolled lip can be obtained.

5) The plastic deformation is basically concentrated in the area of rolled lip.

\section{References}

[1] K.H. Kim, T.K. Ryou, H.J. Choi, and B.B. Hwang, "Analysis of the forging process for 6061 aluminium-alloy wheels",Journal of materials processing technology, vol.123, pp.270-276(2002).

[2] Hsu. Yehliang, and Hsu. Mingsho, "Weight reduction of aluminium disc wheels under fatigue constraints using a sequential neural network", Computers in Industry, vol.46, pp.167-169(2001).

[3] D.M. Maijer, W.S. Owen, and R.A. Vetter, "An investigation of predictive control for aluminium wheel casting via a virtual process model”, Journal of materials processing technology, vol.209, pp.1965-1979(2009).

[4] B. Zhang, D.M. maijer, and S.L. Cockcroft, "Development of a 3-D thermal model of low-pressure die cast (LPDC) process of A356 aluminium alloy wheels", Materials Science and Engineeting A, vol.464, pp.295-305(2007).

[5] Jia Jianbo, Xu Yan, and Luo Junting, "Spinning-punch new technology for aluminum alloy plate-wheels forming", International Workshop on Mechanical Automation and Control Engineering, 25-27 June. (2010)pp.3785-3788.

[6] Shan Debin, Lu Yan, and Li Ping, "Experimental study on process of cold-power spinning of Ti-15-3 alloy”,Journal of Materials Processing Technology, vol.115, pp. 380-383( 2001).

[7] Yao Jian-guo, and Murata Makoto, "An experimental study on paraxial spinning of one tube end”,Journal of Materials Processing Technology, vol.128, pp.324-329(2002). 
[8] Xia Qinxiang, Liang Baixiang, and Cheng Xiuquan, "Influence of nominal reduction of the blank radius per path on the neck spinning of oblique tubes",Journal of Guangdong Non-Ferrous Metals, vol.15, pp.591-597(2005).

[9] Kuang Weihua, Xia Qinxiang, and Ruan Feng, “3D FEM numerical simulation and experimental study on symmetric thin-wall tube neck-spinning",Journal of Harbin Institute of Technology, vol.13, pp.315-319(2006).

[10]Dachang, and Gao Xicheng, "Study on the deformation mode of conventional spinning of plates",Journal of Materials Processing Technology, vol.91, pp.226-230(1999). 